\title{
RISK FACTORS FOR UNDERNUTRITION IN CHILDREN UNDER FIVE YEARS OF AGE IN TENOM, SABAH, MALAYSIA
}

Eric Tan Chee How ${ }^{1,2,4}$, Suzana Shahar ${ }^{3}$, Fredie Robinson ${ }^{2}$, Abdul Marsudi bin Manah ${ }^{4}$, Mohd Yusof Ibrahim $^{2}$, Mohammad Saffree Jeffree ${ }^{2}$, Syed Sharizman Syed Abdul Rahim ${ }^{2}$ and Aza Sherin binti Mohd Yusuff ${ }^{2}$

\author{
${ }^{1}$ Tenom District Health Office, Ministry of Health Malaysia, Tenom, Sabah, Malaysia \\ ${ }^{2}$ Department of Community Health and Family Medicine, Faculty of Medicine and Health Sciences, University Malaysia \\ Sabah, 88400 Kota Kinabalu, Sabah, Malaysia \\ ${ }^{3}$ Faculty of Health Sciences, Universiti Kebangsaan Malaysia \\ ${ }^{4}$ Keningau Area Health Office, Ministry of Health Malaysia, Keningau, Sabah, Malaysia
}

\section{Corresponding author: Eric Tan Chee How}

Email: erictancheehow@yahoo.com

\begin{abstract}
Undernutrition is the result of complex interplay of factors such as household food security, childcare, feeding practices, nutrition and sanitation. Therefore, this study aimed to determine the prevalence of stunting, wasting, underweight based on WHO child growth standards 2006 and undernutrition based on Composite Index Anthropometric Failure (CIAF) and its association with the biological, behavioural, socio-economic and physical environment factors among children under-5 years. This was a cross sectional study involving children aged between 6 and 59 months recruited through stratified random sampling from the Tenom district. Sociodemographic background was obtained from mothers via a questionnaire. Height and weight measurements were measured using standardised instrument. The height-for-age, weight-for-age and BMI-for-age were classified according to the WHO Child Growth Standard 2006. Bivariate analysis and multivariate logistic regression analysis were conducted. The prevalence of undernutrition based on CIAF was $42.3 \%$, underweight $34.7 \%$, stunting $33.3 \%$ and wasting $10.0 \%$. After adjusting for all confounders, childhood undernutrition was significantly associated with unimproved sanitation (adjusted OR 2.98, 95\% CI: 1.082 to 8.225 ) and frequent illness (adjusted OR 2.07, 95\% Cl: 1.015 to 3.274). These findings support the association of biological and physical environmental factors with the nutritional status of children under-5 years old.
\end{abstract}

Keywords: undernutrition, risk factor, malnutrition, children, Malaysia

\section{INTRODUCTION}

Undernutrition remains to be the underlying cause to the mortality and morbidity of children globally despite being preventable ${ }^{7}$. Double burden of malnutrition is an emerging public health concern in countries which are saddled with undernutrition while having concurrent rise of overweight and obesity. Undernutrition is widespread in the developing countries as compared to the developed countries and unfortunately children is the most vulnerable group to undernutrition.

Malaysia is an emerging upper middle-income country however the country is now facing the double burden of malnutrition. The National Health and Morbidity survey (NHMS) 2016 reported that the prevalence of stunting, underweight and wasting in 2016 among Malaysian children under5 years were $20.7 \%, 13.7 \%$ and $11.2 \%$ respectively ${ }^{8}$. Meanwhile based on NHMS 2006, prevalence of stunting, and underweight in Malaysia were reported as $17.2 \%$ and $12.9 \%$ respectively ${ }^{10}$.In contrast, prevalence of stunting, underweight and wasting in Sabah and Labuan based on NHMS 2016 were 23.5\%, $15.2 \%$ and $5.3 \%$ respectively which signifies that the prevalence of stunting and underweight were higher than the national average ${ }^{8}$.

Undernutrition is the result of complex interplay of factors such as infections, inadequate feeding, child care practices, sanitation and poor access to healthcare. However, as yet little is known about the role of these complex factors on undernutrition among children under- 5 years from the east of Malaysia namely Sabah. Therefore, this study aimed to determine the prevalence of stunting, wasting, underweight and undernutrition based on Composite Index Anthropometric Failure (CIAF) and its association with the biological, behavioural, socio-economic and physical environment factors among children under- 5 years in Tenom, Sabah.

\section{METHODS}

The study design of this research was a cross sectional analytical study which was conducted in the district of Tenom in the state of Sabah from 1st of March to 31st of March 2018. The sampling frame is children under-5 years who is under follow up with the 12 public funded health clinics in the district of Tenom within the study period 
and samples were collected via stratified random sampling method from this health facilities. Children under- 5 years were eligible for the study if they are a Malaysian citizen and resident of Tenom. Children who had mental disorder, physically disability or suffering any serious disease were excluded from this study. Prior to the commencement of the study, written approvals were obtained from the Medical Research and Ethics Committee from the Ministry of Health Malaysia (NMRR-17-3000-38960) and from University Malaysia Sabah (JKEtika1/18(8)). There were two sets of respondents, the children and their mothers or caregivers. Informed consent was obtained from the adult respondents and conformed to the Malaysian ethical standard for research.

The sample size of 300 was calculated according to the formula outlined by Daniel $^{3}$ is used for calculation of the sample size $n=Z^{2} P(1-P) / d^{2}$ where $\mathrm{n}$ is the sample size $\mathrm{Z}$ represents the confidence interval, $P$ is the prevalence $(23.5 \%)$ and $d$ is precision. The absolute precision value in this research study is set at 5 percentage points which is 0.05 as suggested by Naing et $\mathrm{al}^{13}$ that if the prevalence is between $10 \%$ to $90 \%$, then the precision value of $5 \%$ is the suitable value. Assuming $95 \%$ of confidence level, the sample size for this study is calculated as $n=1.96^{2} \times(0.235(1$ $\left.0.235) / 0.05^{2}\right)=276$. Therefore, 300 samples were collected for this research study. Sample data was collected through an interview.

\section{Questionnaire}

Community nurses from all the 12 health facilities in the district of Tenom were trained by the researcher for the administration of the questionnaires and interview sessions. Face to face interviews were conducted on all respondents. These questionnaires were pretested on 25 children's mother or caretaker to ensure that the format, the wording and sequencing is correct. Back-to-back translation was done to translate the questionnaire from English to Malay language. The questionnaire is divided into four sections such as demographic information of the child, background information regarding the parents/caregiver, classification of the nutritional status of the child and finally physical environment factors (water supply and sanitation).

\section{Anthropometric measurements}

The weight measurements of infants or children less than 2 years old were conducted in the recumbent position on a Seca infant weighing scale. The length of the infant or children less than 2 years were measured on a recumbent measuring board (accuracy of $0.1 \mathrm{~cm}$ ). The measurement of children aged between 2 years to 5 years old were asked to step on the Seca digital weighing scale (accuracy of $0.1 \mathrm{~kg}$ ) barefooted in light weight clothing and standing straight on a flat surface with eyes looking straight forward. Besides that, to obtain the height of the children under-5 years, the child is required to stand upright against a wall where the child height is measured with a Seca stadiometer. The anthropometric readings were measured twice and the mean of those two readings were calculated and used for the data analysis. Z-scores for BMl-for-age and height-for-age, weight-forage were determined and classified using WHO AnthroPlus software into stunting, wasting and underweight.

\section{Statistical analysis}

Data that were obtained from the questionnaires were then cleaned, edited, coded and analysed with IBM Statistical Program for Social Sciences (SPSS) version 25. The prevalence of undernutrition is measured based on the Composite Index of Anthropometric Failure (CIAF) which includes the prevalence of stunting, wasting and underweight among children under-5 years in the district of Tenom. Composite Index of Anthropometric Failure (CIAF) is measured via totalling up all the subgroup anthropometric failure such as wasting only, wasting and underweight, wasting, stunting and underweight, stunting and underweight and stunting only.

Descriptive analysis was conducted on the demographic and socioeconomic characteristics of the study participants. The descriptive statistics were presented as count and percentages for each categorical variable. Univariate analysis with Chi square were used to evaluate the association between the outcome which was undernutrition based on Composite Index Anthropometric Failure (CIAF) on each of the separate independent variable to identify any independent factors that were associated with undernutrition among children under-5 years. Variables that were being analysed and recorded probability less than 0.05 were considered statistically significant as it would reject the null hypothesis. Chi square can measure the strength of the relationship between the independent and dependent variable. However, chi square cannot measure the direction of the relationship between the independent and dependent variable. Hence, multivariate analysis by Logistic regression was done as a risk assessment for the selected variables that shows significant difference in the bivariate analysis producing adjusted odds ratio and $95 \%$ confidence interval.

\section{RESULTS}

A total of 300 children living in the district of Tenom were included in this analysis with a 92\% response rate and among which $50 \%$ were boys. The mean age of the children were $3.38 \pm 1.44$ 
years. Nutritional status among under-5 children in Tenom 2018 is presented in Table 1. The prevalence of undernutrition based on CIAF among under-5 children in Tenom in 2018 was 42.3\%. Prevalence of underweight, stunting and wasting were $34.7 \%, 33.3 \%$ and $10.0 \%$ respectively. Demographics and socioeconomic characteristics of children aged 0-60 months in Tenom 2018 is presented in Table 2. With regards to ethnicity, majority is Murut $(69.3 \%)$ followed by Kadazan-dusun (15\%), Malay (3.3\%), Chinese $(2.7 \%)$ and other ethnicities such as Indian and other mixed ethnicities (10\%).

Overwhelming of the children's birthweight were above 2 kilograms (96.3\%). Almost all the children were immunised (99\%) as per schedule of immunisation. Majority of the children had preceding birth interval greater than 24 months (72\%). Majority of the mothers or caretakers had secondary school education $(65.7 \%)$ followed by primary school education (20.7\%), diploma or tertiary education $(11.0 \%)$ and only $2.7 \%$ of them did not attend school. In contrast, majority of father them had secondary school education $(65.7$ $\%)$ followed by primary school education (23.6\%), diploma or tertiary education (8.3\%) and only $3.4 \%$ of them did not attend school. It was reported that most of the households earned less than RM 1050 per month $(71.7 \%)$. More than half of the children were living in households with 5 or less members (62\%). Overwhelming majority of the mothers were housewife 215 (85.3\%).

Behavioural practices and physical environment of the respondents and children aged 0-60 months in Tenom 2018 is presented in Table 3. An overwhelming majority of children were being taken care by mother (96.3\%). Most of the mothers had less than 4 times history of pregnancy (70\%). Majority of mothers breastfed their children up to 12 months (44\%) whereas $40 \%$ of mothers breastfed beyond 12 months and only $16 \%$ mothers breastfed less than 6 months. Majority of the mothers started to introduce complementary feeding at the age of 6 months and above (96.7\%). The longest duration of complementary feeding was 6 months and above (96.7\%). Majority of the frequency of complementary feeding was 4 or more than 4 times per day (62.7\%). Overwhelming majority of mothers reported that their daily food supplies were adequate (97\%). Most of parents were found to be smokers $(65.3 \%)$. It has been reported that most of households received treated water (88\%) and improved sanitation (69\%).

Relationship of the undernutrition in children with the risk factors was observed using chi-square test (Table 4a,4b). Birthweight of the child, frequency of illness, deworming status, smoking status, education level of father and mother, mother's occupation, total household income, source of water supply and type of sanitation were found to be significant risk factors for undernutrition using univariate analysis $(\mathrm{p}<0.05)$. Statistically significant factors were further assessed using multivariable logistic regression analysis (Table 5) to adjust for confounders.

Frequent illness and unimproved sanitation have been found to be independently associated with undernutrition in children under-5 years in Tenom. The risk of being undernourished among children using unimproved sanitation were 2.9 times higher compared to using proper improved sanitation (adjusted odds ratio 2.983, 95\% confidence interval between 1.082 to 8.225 ). Frequent illness was 2.1 times higher risk of being undernourished compared to not frequently falling sick (adjusted odds ratio 2.068, 95\% confidence interval between 1.015 to 3.274 ).

Table 1: Nutritional status among under-5 children in Tenom 2018

\begin{tabular}{lc} 
Nutritional status & Frequency (\%) \\
\hline & \\
Underweight & $104(34.7)$ \\
Stunting & $100(33.3)$ \\
Wasting & $30(10.0)$ \\
Undernutrition based on CIAF & $127(42.3)$ \\
No undernutrition & $173(57.7)$
\end{tabular}


Table 2: Socio-demographic characteristics of the children and respondents

\begin{tabular}{|c|c|c|}
\hline Characteristics & $\mathbf{N}$ & $\%$ \\
\hline \multicolumn{3}{|l|}{ Age group of children (months) } \\
\hline$<10$ & 22 & 7.3 \\
\hline $10-20$ & 81 & 27.0 \\
\hline $21-30$ & 58 & 19.3 \\
\hline $31-40$ & 67 & 22.3 \\
\hline $41-50$ & 43 & 14.3 \\
\hline $51-60$ & 29 & 9.7 \\
\hline \multicolumn{3}{|l|}{ Sex of the children } \\
\hline Male & 150 & 50.0 \\
\hline Female & 150 & 50.0 \\
\hline \multicolumn{3}{|l|}{ Ethnic group of the children } \\
\hline Murut & 208 & 69.3 \\
\hline Dusun & 45 & 15.0 \\
\hline Malay & 10 & 3.3 \\
\hline Chinese & 7 & 2.3 \\
\hline Others & 30 & 10.0 \\
\hline \multicolumn{3}{|l|}{ Birth weight $(\mathrm{kg})$ of the child } \\
\hline$\leq 2$ & 11 & 3.7 \\
\hline$>2$ & 283 & 96.3 \\
\hline \multicolumn{3}{|c|}{ Immunization status of the child } \\
\hline Completed as per schedule & 297 & 99.0 \\
\hline Not complete & 3 & 1.0 \\
\hline \multicolumn{3}{|l|}{ Preceding birth interval } \\
\hline$<24$ months & 35 & 11.7 \\
\hline$\geq 24$ months & 216 & 72.0 \\
\hline Primigravida & 49 & 16.3 \\
\hline \multicolumn{3}{|c|}{ Education qualification of mother/caretaker } \\
\hline No schooling & 8 & 2.7 \\
\hline Primary school & 62 & 20.7 \\
\hline Secondary school & 197 & 65.7 \\
\hline Diploma and above & 33 & 11.0 \\
\hline \multicolumn{3}{|c|}{ Education qualification of father } \\
\hline No schooling & 10 & 3.4 \\
\hline Primary school & 68 & 22.6 \\
\hline Secondary school & 197 & 65.7 \\
\hline Diploma and above & 25 & 8.3 \\
\hline \multicolumn{3}{|l|}{ Occupation of mother } \\
\hline Working mother & 44 & 14.7 \\
\hline Housewife & 256 & 85.3 \\
\hline \multicolumn{3}{|l|}{ Total Household income (RM) } \\
\hline Above poverty rate & 85 & 28.3 \\
\hline Below poverty rate & 215 & 71.7 \\
\hline \multicolumn{3}{|l|}{ Household family size } \\
\hline Five and less & 186 & 62.0 \\
\hline Six and above & 114 & 38.0 \\
\hline
\end{tabular}


Table 3: Behavioural practices and physical environment of the respondents and children aged 0-60 months in Tenom 2018

\begin{tabular}{|c|c|c|}
\hline Characteristics & $\mathbf{N}$ & $\%$ \\
\hline \multicolumn{3}{|l|}{ Childcare } \\
\hline Mother & 289 & 96.3 \\
\hline Others & 11 & 3.7 \\
\hline \multicolumn{3}{|c|}{ Number of mother's pregnancies } \\
\hline$<4$ & 210 & 70.0 \\
\hline$\geq 4$ & 90 & 30.0 \\
\hline \multicolumn{3}{|c|}{ Duration of breastfeeding (months) } \\
\hline$<6$ & 48 & 16.0 \\
\hline $6-12$ & 132 & 44.0 \\
\hline$>12$ & 120 & 40.0 \\
\hline \multicolumn{3}{|c|}{$\begin{array}{l}\text { Age of introduction of complementary feeding } \\
\text { (months) }\end{array}$} \\
\hline$<6$ & 10 & 3.3 \\
\hline$\geq 6$ & 290 & 96.7 \\
\hline \multicolumn{3}{|c|}{ Duration of complementary feeding (months) } \\
\hline$<6$ & 10 & 3.3 \\
\hline$\geq 6$ & 290 & 96.7 \\
\hline \multicolumn{3}{|c|}{ Frequency of complementary feeding } \\
\hline$<4$ times per day & 112 & 37.3 \\
\hline$\geq 4$ times per day & 188 & 62.7 \\
\hline \multicolumn{3}{|l|}{ Marital status of mother } \\
\hline Married & 297 & 99.0 \\
\hline Others & 3 & 1.0 \\
\hline \multicolumn{3}{|l|}{ Food supply daily } \\
\hline Sufficient & 291 & 97.0 \\
\hline Insufficient & 9 & 3.0 \\
\hline \multicolumn{3}{|l|}{ Parental smoking status } \\
\hline Parent does not smoke & 104 & 34.7 \\
\hline Parents smokes & 196 & 65.3 \\
\hline \multicolumn{3}{|l|}{ Source of water supply } \\
\hline Treated water & 264 & 88.0 \\
\hline Others & 36 & 12.0 \\
\hline \multicolumn{3}{|l|}{ Type of sanitation } \\
\hline Improved sanitation & 265 & 88.3 \\
\hline Unimproved sanitation & 35 & 11.7 \\
\hline
\end{tabular}


Table 4a: Bivariate analysis of risk factors leading to Undernutrition among under-5 children in Tenom 2018

Factors Undernutrition Yes (n) No $(n)$ $p$-value

Biological

Age of the children (months) 
Table 4b: Bivariate analysis of risk factors leading to Undernutrition among under-5 children in Tenom 2018

\begin{tabular}{lccc}
\hline Factors & \multicolumn{2}{c}{ Undernutrition } & $p$-value \\
& Yes $(\mathrm{n})$ & No $(\mathrm{n})$ & \\
\hline
\end{tabular}

Frequency of complementary

\section{feeding}

$<4$ times per day

$\geq 4$ times per day

Smoking status

Parent does not smoke

Parents smokes

Socioeconomic

Household family size

Five and less

Six and above

Education qualification of mother/ caretaker

No schooling

Primary school

Secondary school

Diploma and above

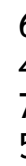

2

$40 \quad 22$

$76 \quad 121$

$5 \quad 28$

Education qualification of father No schooling

46

Primary school

Secondary school

77

24

Diploma and above

2

120

23

Occupation of mother

Working mother

Housewife

8

Total Household income

Above poverty level

Below poverty level

20

73

$<0.001$

107

100

Food supply daily

Adequate

Inadequate

124

3

167

0.6

Physical environment

Source of water supply

Treated water

Others

105

159

0.02

22

Type of sanitation

Septic tank/sewage system

Others 
Table 5: Logistic regression analysis for selected risk factors for undernutrition

\begin{tabular}{ll}
\hline Variables & aOR $(95 \% \mathrm{Cl})$
\end{tabular}

Birth weight $(\mathrm{kg})$ of the child

$\leq 2$

$>2$

Frequency of illness

Infrequent

Frequent

Smoking status

Parent does not smoke

Parents smokes

\section{Deworming status}

Yes

No

Others

Education qualification of mother/

caretaker

No schooling

Primary school

Secondary school

Diploma and above

\section{Education qualification of father}

No schooling

Primary school

Secondary school

Diploma and above

Occupation of mother

Working mother

Housewife

Total Household income

Above poverty rate

Below poverty rate

Source of water supply

Treated water

Others

Type of sanitation

Septic tank/sewage system

Others
1

$0.535(0.121-2.359)$

1

$2.068(1.015-3.274)$

1

$1.328(0.709-2.488)$

1

$0.663(0.329-1.337)$

$0.224(0.099-0.506)$

1

$0.510(0.078-3.314)$

$0.217(0.034-1.368)$

0.377 (0.039 - 3.628)

1

$3.271(0.623-17.173)$

$2.441(0.455-13.097)$

$0.314(0.028-3.558)$

1

$2.822(0.829-9.607)$

1

$0.823(0.350-1.939)$

1

$1.286(0.537-3.077)$

1

$2.983(1.082-8.225)$

\section{DISCUSSION}

The study results revealed that the prevalence of underweight, stunting and wasting in Tenom were higher than the national average ${ }^{8}$. This could be due to the presence of several independent risk factors of undernutrition that are present in Tenom namely unimproved sanitation and frequent illnesses. Furthermore, undernutrition was observed to be the highest frequency among children age of $10-20$ months. Thus, it is crucial to devise strategies to address undernutrition in children by focusing its interventions on the critical 1000 days window-period from conception to 2 years of age among the population of Tenom.

Unimproved method of sanitation was a significant predictor of undernutrition with an adjusted odds ratio of 2.983 (95\% confidence interval between 1.082 to 8.225 ). This finding is further corroborated with a study in Mali ${ }^{16}$ which shows that provision of improved sanitary 
facilities can improve the growth of the child by reducing frequency of diarrhoea. Without an improved sanitation system, the faeces that were defecated were not properly disposed resulting in contamination of the rivers or the nearby surroundings. This is further complicated by the fact that some household in the rural areas do not receive water treated water resulting in family members of those household resort to collect water from the nearby rivers that may be contaminated with faeces causing outbreak of faecal-oral infections namely cholera and typhoid fever.

However, a study conducted in Kenya ${ }^{14}$ reported no significant improvement of child growth despite improvement in the sanitation facilities. This lack of association could be explained as it compares intervention that of households from unimproved sanitation rather than from a lower baseline sanitation coverage such as open defecation with high prevalence of diarrhoea to a better improved sanitation. Similarly, another previous study conducted in Terengganu, Malaysia ${ }^{23}$ also failed to find any association between sanitation and undernutrition $A$ possible explanation could be that the coverage of improved sanitation is higher in peninsular Malaysia, thus no association are observed. This lack of association is consistent with previous study conducted in other developing countries such as Zambia ${ }^{12}$, Ghana ${ }^{19}$ and Vietnam ${ }^{6}$.

Frequent illness increased likelihood of being undernourished by 2 folds among under 5 children in Tenom. This finding is corroborated with previous study by Endris et $\mathrm{al}^{5}$ which reported that frequent illness is an important determinant for child malnutrition. Previous studies conducted in Terengganu, Malaysia ${ }^{23}$ and Bangladesh ${ }^{9}$ also reported similar findings of which health and biological factors associated with nutritional status of children. In contrast, an earlier study conducted in Kelantan, Malaysia ${ }^{22}$ did not find any association between the frequency of illness of the child with stunting, wasting and underweight. The correlation between frequency of illness and undernutrition are evident because recurrent episodes of illness such as diarrhoea can cause large amount of water and nutrient to be loss from the body leading eventually to undernutrition. In addition, recurrent illness also may impair the appetite of the child resulting in reduction of dietary intake which subsequently leads to undernutrition. Undernutrition in turn would weaken the immune system causing the children to be susceptible to more severe, frequent and prolonged illness perpetuating somewhat of a vicious cycle.
This present study has limitations that warrant for discussion. The study is a cross-sectional study which does not allow for causal inferences to be made. In addition, the data collection is only confine to one district in Sabah, hence may not be able to be generalised to the entire state of Sabah and may not represent the whole country. Another limitation of the present study was that the information that was obtained from mothers and caretakers of the child was subject to information bias. A thorough dietary assessment for instance dietary recall were not conducted in this present study to determine the dietary intake and appetite of the child. The study was conducted on Malaysian children in the district of Tenom that were under the follow up with the respective health facilities which excludes the non-citizen children that did not seek healthcare services from the Ministry of Health of Malaysia.

\section{CONCLUSION}

Undernutrition remains to be the underlying health problems potentially lead to the mortality and morbidity among children under- 5 years in Tenom district of Sabah. After adjusting for all confounders, childhood undernutrition was significantly associated with unimproved sanitation (adjusted OR 2.98, 95\% Cl: 1.082 to 8.225) and frequent illness (adjusted OR 2.07, 95\% $\mathrm{Cl}: 1.015$ to 3.274$)$. These findings support the association of biological and physical environmental factors with the nutritional status of children under-5 years old. Further studies should perform dietary assessment of the children to determine their dietary intake and to evaluate its relationship with undernutrition. Since undernutrition is the result of complex interplay of factors such as biological factors and physical environment factors hence a multisectoral approach with local communities, nongovernmental organizations, governments and international agencies is essential to combat undernutrition.

\section{ACKNOWLEDGEMENT}

The authors would like to thank the Director General of Health Malaysia for the permission to publish this paper. The authors would also like to thank all the participating health clinics and nurses working in the Ministry of Health for facilitating data collection. The authors are also indebted to the mothers of the children or caretakers for their participation in the study.

\section{CONFLICT OF INTEREST}

The authors declare that they have no competing financial interest. This is a self-funded research. 


\section{REFERENCES}

1. Ahsan $\mathrm{S}$, Mansoori $\mathrm{N}$, Mohiuddin $\mathrm{SM}$ et al. Frequency and determinants of malnutrition in children aged between 6 to 59 months in district tharparkar, a rural area of Sindh. Journal of the Pakistan Medical Association 2017; 67(9):1369-1373.

2. Chowdhury MR, Rahman MS, Khan MM et al. Risk factors for child malnutrition in Bangladesh: A multilevel analysis of a nationwide population-based survey. Journal of Pediatrics 2016; 172:194-201.

3. Daniel. Biostatistics: A Foundation for Analysis in the Health Sciences. Statistics in Medicine 1999; 20(2):324-326.

4. Delisle $\mathrm{H}$, Batal $M$. The double burden of malnutrition associated with poverty. The Lancet 2016; 387(10037):2504-2505.

5. Endris N, Asefa H, Dube L. Prevalence of Malnutrition and Associated Factors among Children in Rural Ethiopia. BioMed Research International 2017; 1-6.

6. Hien NN, Kam S. Nutritional status and the characteristics related to malnutrition in children under five years of age in Nghean, Vietnam. Journal of Preventive Medicine and Public Health 2008; 41(4):232-240.

7. Horton. Executive Summary of The Lancet Maternal and Child Nutrition Series. The Lancet 2013; 5(1):1-11.

8. Institute for Public Health. National Health And Morbidity Survey 2016: Maternal And Child Health $(\mathrm{MCH})$. Kementerian Kesihatan Malaysia, http: / /www.iku.gov.my/images/IKU/Documen t/REPORT/2016/NHMS2016ReportVolumell-

MaternalChildHealthFindingsv2.pdf. Accessed April 07, 2019

9. Jesmin A, Yamamoto SS, Malik AA et al. Prevalence and determinants of chronic malnutrition among preschool children: A crosssectional study in Dhaka City, Bangladesh. Journal of Health, Population and Nutrition 2011; 29(5):494-499.

10. Khor GL, Noor Safiza $M N$, Jamalludin $A B$ et al. Nutritional status of children below five years in Malaysia: Anthropometric Analyses from the Third National Health and Morbidity survey III (NHMS, 2006). Malaysian Journal of Nutrition 2009; 15(2):121-136.

11. Makoka D, Masibo PK. Is there a threshold level of maternal education sufficient to reduce child undernutrition? Evidence from Malawi,
Tanzania and Zimbabwe. BMC Pediatrics 2015; 15(1):96.

12. Masiye F, Chama C, Chitah B et al. Determinants of Child Nutritional Status in Zambia: An Analysis of a National Survey. Zambia Social Science Journal 2010; 1(1).

13. Naing, Winn R. Practical Issues in Calculating the Sample Size for Prevalence Studies. Archives of Orofacial Sciences 2006; 1(Ci):9-14.

14. Null C, Stewart CP, Pickering AJ et al. Articles Effects of water quality, sanitation, handwashing, and nutritional interventions on diarrhoea and child growth in rural Kenya: a cluster-randomised controlled trial. The Lancet Global Health 2018; 6(3): e316-e329.

15. Osei A, Pandey P, Spiro D et al. Household Food Insecurity and Nutritional Status of Children Aged 6 to 23 Household food insecurity and nutritional status of children aged 6 to 23 months in Kailali District of Nepal, l. Food and Nutrition Bulletin 2010; 31(4):483-494.

16. Pickering AJ, Djebbari $\mathrm{H}$, Lopez $\mathrm{C}$ et al. Effect of a community-led sanitation intervention on child diarrhoea and child growth in rural Mali : a cluster-randomised controlled trial. Lancet Glob Health 2015; 3(11):e701-11.

17. UNICEF. Improving child nutrition: The achievable imperative for global progress. Division of Communication, UNICEF 2013.

18. UNICEF / WHO / World Bank Group. (2017). Levels and Trends in Child Malnutrition2017.https://data.unicef.org/wpcontent/uploads/2017/06/JME-

2017_brochure_June-25.pdf [Accessed April 07, 2019].

19. Van De Poel E, Hosseinpoor AR, Jehu-Appiah C, Vega J, Speybroeck N. Malnutrition and the disproportional burden on the poor: The case of Ghana. International Journal for Equity in Health 2007; 6:1-12.

20. WHO. The new WHO child growth standards. Paediatria Croatica Supplement 2006; 52(SUPP.1):13-17.

21. WHO. Improving nutrition outcomes with better water, sanitation and hygiene: Practical solutions for policy and programmes 2015.

22. Cheah WL, Wan Muda WA, Mohd Hussin ZA, Thon CC. Factors associated with undernutrition among children in a rural district of Kelantan, Malaysia. Asia-Pacific Journal of Public Health 2012; 24(2):330-342. 
23. Wong HJ, Moy FM, Nair S. Risk factors of malnutrition among preschool children in Terengganu, Malaysia: A case control study. BMC Public Health 2014; 14(1):785.

24. Zainal Badari, Shamsul Azahari and Arcot, Jayashree. Development of a healthy food and nutrition plan (Malaysia Healthy Food Plan Basket [MHFPB]) for lower-income households in Peninsular Malaysia. Malaysian Journal of Consumer and Family Economics 2014. 